International Journal of Instruction e-ISSN: 1308-1470 • www.e-iji.net

Article submission code: 20191117003741

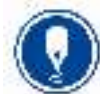

October $2020 \bullet$ Vol.13, No.4

p-ISSN: 1694-609X

pp. $29-46$

Received: 17/11/2019

Revision: 01/06/2020
Accepted: 22/06/2020

OnlineFirst:06/10/2020

\title{
The Impact of Exchanged Information between School and Parents at the Level of Parent Involvement in School
}

\section{Vlora Sylaj}

Asst. Prof., Department of Pedagogy at Faculty of Education, University of Prishtina "Hasan Prishtina", Prishtina, Kosovo, vlora.sylaj@uni-pr.edu

The study's purpose was to analyse the involvement of parents in school and the information as an influential factor on this process. The other purpose was to examine teachers', parents' and school principals attitudes on the prevention of violence between students in school. In our study violence is the case for studying the involvement of the family in school. The subjects of the study were 298 parents of the urban environment and 394 parents of the rural environment, 400 rural environment teachers and 299 urban environment teachers involved in the quantitative study, were invented and selected through random sampling groups to take part in the research. 9 interviews were conducted with parents, 11 with teachers and 5 with school principals. Therefore, the mixed approach of the research was conducted. The total number of the involved in the study was 1416 . The study used a mixed research approach, using in-depth interviews and a questionnaire designed for this study, while the research data were analyzed through descriptive and inferential statistics. The results support the assumptions of the study, by showing that the information has a positive link with statistical significance with the level of the parents' involvement in school. On the other side there exist two contradicting ascertainments between parents and the school about their perceptions and practices of information. The interviews have discovered a very concerning case and the fact that a part of the psychological violence between students does not get reported to the family or school.

Keywords: information, prevention, violence, student, family, parent involvement

\section{INTRODUCTION}

Violence among pupils at school is one of the reasons of family school collaboration. In fact, there are many reasons why family should be more involved in school including learning and child safety. "Parents' involvement in various studies is defined as representative of school or home-based behaviors and practices which includes parental aspirations, expectations, attitudes and beliefs of parents in relation to child education." (Georgiou, 2007). Adequate family involvement implies the need for moving beyond formal involvement towards more cooperative partnership. Family involvement refers to

Citation: Sylaj, V. (2020). The Impact of Exchanged Information between School and Parents at the Level of Parent Involvement in School. International Journal of Instruction, 13(4), 29-46. https://doi.org/10.29333/iji.2021.1413a 
a wide range of activities through which parents, grandparents, older siblings as well as other relatives contribute to student learning (Cori \& Jennifer, 2003). Literature provides different definitions on family involvement in school. This study adopts the terms family involvement as opposed to parents as the idea is to refer to the broader family actors. Why? Because when we talk about inclusion, we do not imply only inclusion of families, whose children have experienced violence and that now we want to avoid repeating, but to be value to all families, so that prevention happens in a timely and continuous manner.

Families can facilitate schools if they reorganize to develop violence prevention and reduction programs. Partnerships between school personnel and family members, including the students themselves, can work to bring about a non-violent school environment. School personnel require knowledge to engage families as partners from a strengths perspective. Information and strategies are provided for school personnel as they enhance family strengths and work with families to create non-violent atmospheres in schools

Another element that is considered to play a major role toward violence is poverty. Researchers have repeatedly established that poverty and its contextual life circumstances are major determinants of violence (Lang,1998 \& American Psychological Association, 1993). There is another theory according to which intrauterine growth, early trauma, infant-child attachment, and other influences play a major part in brain development. It is thought that abuse is an ingredient that could lead a child to act violently. Buchanan (1996), 30-40\% of children who suffer abuse or neglect goes on to abuse or neglect their own children.

Another contributor to violence is considered to be stress. Stress is the way that some people react physically and emotionally to various events that happens to and around them. Stress affects people differently and a variety of things can cause people to be stressed (Clarke et al., 1988). A factor that has been linked to violence is asocial behavior Walker et al. (1995)

Another theory on violence considers that perceived that violent behavior is learned from family members, neighborhood environment, and peer groups (Loeber, R., \& Stouthamer-Loeber, M., 1986). "The students' social experience in elementary schools mediates the relationship between personal and family experience and school violence committed by students against other students and teachers. That is, as students' negative personal and family experiences increase, they have lower levels of school engagement and poorer social interaction with students and teachers on school grounds. In turn, their likelihood of becoming involved in school violence will increase" (Kang \& Aston, 2011, p. 150-166).

But we have other researchers as well Gottfredson \& Hirschi (1990) felt that the potential for violent behaviour is inherent in the chemical makeup of the human body. Miller (1996) stated that violence is an inborn trait, which leads people toward aggressive and violent behaviour. 
Formal collection (e.g., phones, report forms, drop boxes) procedures may help to assure parents of victims that the school regards the issue as serious and is taking steps to address the problem. Such collection procedures may also be useful when consulting with parents of perpetrators, who can be presented with the factual information if they minimize or deny their child's aggression. Schools can also establish formal procedures for parents to report victimization and create a bullying hotline whereby students can anonymously report bullying. Services such as Google Voice enable schools to create a free phone number that can be routed to ring other lines at the school. Using a service such as Google Voice creates a transcript of the voicemails, which allows for easy screening to determine which calls should be responded to immediately ( Kolbert, B,J.;Schultz,D. \& Crothers,M,L.,2014)

School counselors can also create a program website, blog, and Twitter account to keep parents and their school community informed (Mason \& Schultz, 2013; Sampson, 2013). At Kolbert, B,J.; Schultz,D. \& Crothers,M,L.(2014) we find that in addition to information about bullying, parents need data about all of the various events and activities that are taking place at school. When parents know what is going on at school, they tend to feel more connected and informed about what is going on in their children's lives. Moreover, parents and families are more able to participate more fully in events if they know about them in advance. School counselors can encourage administrators and teachers to create a school newsletter highlighting the various events and activities that are occurring periodically throughout the school year" "Using such electronic media, school counselors can share information and keep parents informed about the groups, classroom lessons, and school-wide events hosted by the school counseling program. Parents can subscribe to the school counselor's blog via email and receive updates every time a new post is published. Parents can also follow the school counselor or school counseling program on Twitter to receive updates on blog posts, school information, and resources.

The researcher Shore (2005), in his study finds that 5 to $20 \%$ of all students are victimized by bullies at some point in their school experience. Research has shown that physical attacks or fights without a weapon are the most common incidents, occurring in $64 \%$ of all public schools (DeVoe, Peter, Noonan, Snyder, \& Baum, 2005).

While research conducted on violence in schools has demonstrated that there is no one single cause of school violence, many causes have been associated with school violence (Lerner, 2006).Violent behavior may be correlated with 88 the following: single-parent homes, violent imagery in the media, peer pressure, sense of low self-esteem, exposure to early childhood abuse or neglect, a need to seek respect or attention from others, witnessing violence at home, lack of parental supervision, home environment, bullying, substance abuse, and low socioeconomic level (Lerner, 2006). The causes of violence among students in school are factors like disruptive student behavior, poor attendance rates, and academic failure, as well as stressful school environment (DeVoe et al, 2005).

Research in the last decades have proved that parents' involvement is quite a important in the process of learning children, in their thinking about school and in aspirations them. Children are the most successful student throughout the school if their parents are 
involved school and encourage home learning, regardless of their educational or social level (Epstein, 2001). School-community collaboration and partnership programs and teacher-related parental involvement have quite positive effects on Parents' ability to help their children throughout school years; in the assessment of the parents on the skills of teachers and the quality of teaching; in the opinion of teachers about the possibilities of parents to help their children with home school assignments and students' thinking about school (Becker \& Epstein, 1982; Epstein, 2001). School-family-community partnership improves school curricula and climate at school, offers services and support for families, enhances parenting skills and their leading role, creates links between them parents in school and community and helps teachers in their work. Above all, such partnerships are created to help young people succeed in school and in life (Epstein, 2001).

Epstein (1986) distinguishes six types of involvement parents in school life. Type I Involvement in basic obligations at home (the provision of school supplies, general support and supervision at home); Type II School to home and home to school communications. Type III Assistance at the school (volunteering); Type IV Assistance in learning activities at home; Type V Involvement in school decision-making, governance and advocacy; Type VI Collaboration and exchange with community organizations. They contain activities that can be organized at school, at home and in the community by teachers, pupils, parents, executives and other actors for improving schools, strengthen families, and the increase of pupils success (Epstein, 2001). In their study, Epstein and Dauber (1989) have found out that teachers who have more positive views to the parent involvement, they attach more importance to such practices including organizing meetings with parents of all pupils on school curricula and exchanging with parents both negative and positive outcomes of their pupils' learning. Strengthening the positive attitudes of teachers also correlates with the growth of success in parenting involvement "difficult to reach". When teachers make parental involvement part of daily teaching practices, parents increase interaction with their children at home, have more positive sensation about their ability to help their children, have higher appreciation for teachers in general and pupils improve their attitude and achievements (Epstein, 2001). On the other hand, why is it necessary, among other things, to strengthen the family school partnership, is the fact that: The discovery of the opinion and attitudes of parents, teachers and school directors regarding the level of parental-school cooperation as well as the level of family information from the school on issues related to the pupils and the policies of the school in general.

The objective of the study was the discovery of attitudes, views of family and school about the level of school information family and disclosure of relationship between this factor - information and family and the level of contacts with the school to prevent violence among students. The purpose of the study is to seek ways of optimizing of collaboration of school with the family for coping with violence among pupils.

This study will address the following research question: Does the parent receive enough information about the violence in school and the consequences in case of violence? Do the teachers know the juridical aspect of violence in school? Do we have events from 
school for parents about the prevention of violence? Is the information of parents connected to their involvement in school?

Research hypothesis: the level of partnership between parents and teachers to prevent the violence among students is influenced by shared information between parents and teachers. In function of this purpose, a series of activities are presented that are dealing with knowing the scantling of the phenomenon of violence among pupils, as well as the recognition and pointing out of the factors that determine the level of collaboration of school with the family. This study is important because it affects the information family by school and it establishes the contacts with the family. Also, note that the relationship between these variables is the same in urban and rural areas.

\section{LITERATURE REVIEW}

According to Raffael and Knoff (1999), cooperation in education came with a view of sharing information between families and practitioners. Also, various studies have proven that one cannot wait for the parents to build their own awareness and information in helping their children, or to contact with schools/students, but it should be the school that informs and involves the parents in the school-family-community partnership (Bezati \& Hoxhalari, 2011).

Brubaker et al, (2001) suggest that regular information from school to families on any changes in behaviour of children is more than necessary. Families, the children of which may be aggressive or violent in schools, must informed by the school, and are the best suited people to develop a strategy to manage their own children. Information is very much necessary for school teachers. Communication should be utilized for building a successful partnership between family and school for preventing violence among students, as there is no collaboration between family, educators and members of community if there is no mutual communication in this direction, focused on strong points of parents and students (Epstein et.al, 1993). Researchers consider that the way we realize school- parent communication is definitely important in communication between school and family for preventing violence among students. It is certain that in order for this communication to be effective, it must be positive. In this aspect of necessity for positive communication from school toward family, for family members to believe that their thoughts and feelings are respected, teachers must engage in two-way communication with family members that is positive and supportive. When relationships with families are built on a foundation of positive, healthy communication, problems that may arise throughout the year are more likely to be resolved in a positive way (Ratcliff \& Hunt, 2009).

Setting from Brubaker et al,(2001); Jackson, Henrikson and Foshee (1998) have found that children who perceive that their parents have clear instructions, structured care and support are much less engaged in violent actions with their peers. The educational personnel may offer parental education, and thereby facilitate the parents' job in setting clear boundaries and supporting their children. This information may be shared with parents at any class or year. In terms of assistance to families in preventing violence between students, and this factor in preventing violence, authors Brukaker and Link 
(2001), demand that when informing the families with a view of preventing violence amongst peers, the parents are advised on literature that they must consult in this sense.

According to a study made by Gudlaug, all parents want to be informed on the manner and the persons their children spend their time during or outside school, and the majority of parents consider themselves to be well-versed with the school in these terms (Erlendsdóttir, 2010). Jackson, Henrikson and Foshee (1998) have found that children who think that they parents have clear instructions, structure, caring and support from them, were clearly a little less engaged on violent actions with kids their age. The teachers could offer parental education and could make it easier for parents to put clear boarders and support their children. This information could be shared with children`s parents on every grade level (Brukaker et al, 2001).

When addressing the importance of this factor in the school-family relationship authors Shapley \& Case (2004) underline the need of being careful when sharing information with the family on their child, since one must avoid blaming and judging the family, but also clearly and shortly state the situation, and illustrate with concrete examples. The family must understand that any given problem will not be resolved within days or weeks of sharing information. In this regard, authors recommend that teachers have in mind the feelings of parents/family when sharing information, and then try to concentrate in resolving the problem during the conversation. Again, even the solution will come a bit later. It is rather obvious that this factor is highly relevant, and therefore, one must have regard of its delicacy.

The school can be the one who spreads the important information by children`s help. Most of the families want specific information about the activities that they can do with their children. The teachers can also give helpful instructions even for creating an environment that stimulates the child`s success, like setting of the homework time, reading on free time, exploring different educative topics, and also limiting the time of standing in front of the TV or video games. Schools can also share information on community services and activities that require support and extra opportunity for everyone in the family to have a lesson (Callender \& Hansen, 2004). But when we talk about the importance of this factor on cooperation school-work, the authors Shapley\& Case (2004) let us know that we should be careful when informing the family about their child, because we should avoid blaming and judging the child. But also declare the state clearly, shortly and with examples about the child 's attitude. There are many advantages of informing the family from school and they reflect, most importantly, at the children. Also, the enough information that the family takes from school and the job that it does, just make the cooperation between family and school better. Like the professionalism of the teachers and parent`s awareness about their child`s can open ways for a useful educational partnership (Dusi, 2012). We consider that by informing we can do a lot about preventing the violence between students.

\section{METHOD}

Very little research has studied the relationship between written communication and its impact on parent-teacher collaboration. This study used a quantitative and qualitative 
framework, as following the article we will detail the rationale and hypotheses for this study, and explains the data collection and analysis process.

\section{Research Design}

In order to recognize the problem in its complexity, the mixed methodology was used: survey and interviews. Using these methodologies was seen as necessary to meet the breadth of opinions, experiences, and practices on violence among students in particular, and information family- school collaboration in preventing violence among students.

\section{Participants}

Long-term studies of the effects of family information from the school on the behaviour and success of pupils in school after completing primary or secondary education and longer. We have determined that the reliability level is $95 \%$, with the error limit of $5 \%$, like most other studies. In our study, the population consisted of heads of schools, the teachers, families, and elementary school pupils of Kosovo primary schools. Our sample consists of three layers: family, school (teachers and directors). The sample number for each layer was made in order to fulfill the formula $30 /(2 *$ the number of geographical regions). For sample representation we used MEST statistics. According to MEST statistics, in the eighth grade of lower secondary school in Kosovo there are a total of 30088 pupils, out of which female 15663 and 14425 males.

For a wider representation, we have divided our nationwide population into 14 municipalities. So in the sample we included 14 Kosovo municipalities, except Pristina where we took two schools for study. Then, a school from a village of municipalities taken in the study, a total of 29 schools. To get information on violence among pupils in school with all its features, we also conducted interviews with families, as well as school leaders and teachers. The schools were the ones in which we distributed the questionnaires. Concretely, these interviews were realized; 9 with parents and 11 with teachers, 5 with school principals. The final sample with which the quantitative study analyses was started was $\mathrm{N}=1700$. In the study were included 300 parents from urban environment schools, as well as 300 teachers from urban environment schools in Kosovo, as well as 400 parents from the rural environment school and equally, 400 of rural environment, as well as directors of each school where teachers and families of both environments are involved. After his final clean-up, based on which his analysis was made, was $\mathrm{N}=1416$, which included 298 families in the environment and 394 families of the rural environment, 400 rural environment teachers and 299 urban environment teachers. The sampling for quantitative data, and 25 sample units for the qualitative data.

The reason why the number of respondents in the rural environment is greater is because the population in Kosovo is more extended in this environment. Another reason, "given the limited resources in the rural community, school-to-family collaboration, can be particularly useful for pupils in rural schools". Based on these two reasons, the empirically study we stretch it out at national level in Kosovo. As understood, the study analysed factors related to family cooperation with school in a broader geography that represents the entire population of the country. For by number and geographic extent, it 
is considered to be a representative of the entire primary schools community in Kosovo. In our study population we have assumed that all teachers have the same characteristics in the professional aspect. Families as well. Also, we assume that we have homogeneity even in terms of the regional side. For all schools and urban families we assume that they have the same characteristics, as well as the rural ones.

Table 1

Sample of Research

\begin{tabular}{lll}
\hline Participants & $N$ & $\%$ \\
\hline Teachers of urban schools & 299 & $52.93 \%$ \\
Parents of urban schools & 298 & $47.07 \%$ \\
Teachers of rural schools & 400 & $48.75 \%$ \\
Parents of rural schools & 394 & $52.25 \%$ \\
\hline
\end{tabular}

\section{Instrument}

The study used a questionnaire that addresses study questions connected about the important factors for continued involvement of the family in school, for cooperation in general, and for the prevention of violence among students. For this study, we, as researcher, constructed two questionnaires. One for the family and one for the teachers. In the number of the variables, the questionnaires are the same, both for the family and the teacher, also.

Resemblance, we have also in the names of the sections. Initially, before the data collection was realized, we conducted a pilot with the first variant of the questionnaire with about 25 interviewees. Piloting made us avoid a statement of the questionnaire in which $80 \%$ of respondents did not give an answer, as well as three sections compiled with dichotomous answers, turned them to the Likert scale, for the fact that from all interviewees answered with yes or not.

We estimated that such answers do not enable us an objective perception. This section contains five indicators. For this question, coding has been implemented in the form of a scale, where respondents responded with "Fully Agree", "Agree", "Undecided", "Disagree" and "Not Agree" and the part labelled family trust in school, effective communication, family information, decision-making, support the success of students, the school welcomed family and vice versa, separation of duties and responsibilities, previous experience with the school family. The questionnaire was developed by us as the researchers. Through the questionnaire we measured the perceptions of respondents for informing the school towards the family and vice versa. Has been used a scale with five indicators, designed to measure family and teacher perceptions about the level of family information from the school and its correlation with the level of involvement in the school.

\section{Data Collection Procedure and Data Analysis}

The data were collected from a group of teachers who were trained prior to data collection. The study is divided into two phases. The first phase of the study is the review and examination of existing literature on the problem. In the second phase, we 
applied questionnaires. Before conducting a survey we respected the requirements for quantitative research ethics, such as confidentiality, anonymity, the consent of the persons involved, the right to privacy and the opportunity of attraction.

The data collection process was coordinated with the permission obtained from the Directorate of Education as well as the principals of the schools involved in the research. Questionnaires were distributed to primary and secondary schools in both urban and rural areas to ensure a more heterogeneous and representative sample. During the school visits, we have ensured full confidentiality on data processing and presentation only for scientific purposes. It should be noted that throughout the process of data collection, we have not encountered any hesitation for neither parents nor school teachers to participate in the study. A teacher and a parents needed about 25-30 minutes to complete the questionnaire. After data collection, the database in the SPSS program has initially been created for the teachers' and parent's questionnaires. After inserting all the data, they have been analysed, and the statistical data of results have been obtained.

\section{FINDINGS}

This section focuses on the descriptive analysis of the obtained data in this study. Raw scores were used in the data analyses. All the analyses were performed at significance level .01.

Table 2

Level of Involvement and the Level of Information between Teachers from Urban Areas and Family, According to the Teachers' Attitudes

\begin{tabular}{cccccl}
\hline Variable & Level of involvement & & \\
\hline & Number & Mean & SD & $r$ & sig. \\
\hline Level of information & 300 & 2.6294 & .55160 & .336 & .000 \\
\hline
\end{tabular}

Note.** .Correlation is significant at the level of 0.01 .

The results of our study show that the level of information coming from the school to urban families is only perceived as average. Only $3.2 \%$ of urban families perceive the information coming from the school to be at a high level, while $62.5 \%$ consider it to be poor, while $30 \%$ consider it to be average. Mean responses in assessing the level of information sharing with the schools in urban families were 2.6294 (DS. 55160).

The first objective of the study was to examine the interconnection between the level of involvement and the level of information between teachers from urban areas and family, according to the teachers' attitudes. Through correlation analysis is understood interconnection between variables. The correlation between the meetings and the level of information in urban areas is recorded at: $(r=.336, \mathrm{p}<.000)$. This is a moderate, yet statistically relevant correlation. 
Table 3

Level of Involvement and the Level of Information between Teachers from Urban Areas and Family, According to Family Attitudes

\begin{tabular}{cccccc}
\hline Variable & \multicolumn{2}{c}{ Level of involvement } & & \\
\hline & Number & Mean & SD & $r$ & sig. \\
\hline Level of information & 300 & 2.0873 & .58654 & .133 & .000 \\
\hline
\end{tabular}

Note.**.Correlation is significant at the level of 0.01 .

Then, $64.8 \%$ of urban area teachers consider the information they share with the families to be "average". $22.5 \%$ consider such rate to be "high", while $12.8 \%$ think its "poor". Results show that the majority of teachers consider that their own level of sharing with the families is at an average level, not high. The mean responses in assessing the level of information sharing, according to teachers, in urban areas were 2.0973 (DS. 58654).

Whereas, the second objective of the study was to examine the interconnection between the level of involvement and the level of information between teachers from urban areas and family, according to family attitudes

We have also studied the correlation between the ratio of meetings and information levels in urban areas and we learned that the rate is: $\left(r=.133^{*}, p<0.00\right)$, which may be a weak relation, but statistically relevant.

Table 4

Level of Involvement and the Level of Information between Teachers from Rural Areas and Family, According to the Teachers' Attitudes

\begin{tabular}{llllll}
\hline \multicolumn{7}{c}{ Lariable } & Number of involvement & Mean & SD & $r$ & sig. \\
\hline Level of information & 300 & 2.0178 & .84647 & .249 & .000 \\
\hline
\end{tabular}

Note.**.Correlation is significant at the level of 0.01 .

Another aspect of this study was to investigate the teachers' attitudes about the level of information shared by the school. $436.5 \%$ of the families surveyed consider information-sharing from the schools to be "poor", $28.4 \%$ consider the information sharing to be "high", and $34.8 \%$ to be "medium". We see that information sharing between schools and rural area families shows some difference between "medium" and "poor" levels, while the "medium" level dominates. Rural area families consider the information sharing from schools to be of a medium quality. Mean responses in assessing the level of information sharing with schools in rural families were 2.0178 (DS. 84647). Then we examined the interconnection between the level of involvement and the level of information between teachers from rural areas and family, according to the teachers' attitudes. Further, we engaged into a correlational analysis of information shared and the meetings between schools and families. The correlational rate between the meetings and information levels in rural areas was recorded at: $\left(r=.249^{* *}, p<0.00\right)$, which may be weak, but again statistically relevant. 
Table 5

Level of Involvement and the Level of Information between Teachers from Rural Areas and Family, According to Family Attitudes

\begin{tabular}{cccccc}
\hline Variable & \multicolumn{7}{c}{ Level of involvemen } \\
\hline & Number & Mean & SD & $r$ & sig. \\
\hline Level of information & 300 & 2.5968 & .52272 & .652 & .000 \\
\hline
\end{tabular}

Note.**.Correlation is significant at the level of 0.01 .

Even the teachers of rural areas state the same perception of the families of the same environment. They consider school information sharing to be at a medium level. As per responses of teachers in rural areas, from a total of 315 teachers responding to this question, 117 teachers, or expressed in percentage, 17.9.0\%, express the opinion that the information sharing from the schools is at a "medium" level. 193 teachers, or $29.0 \%$, consider it to be at a "high" level, and 1.2\% "poor". According to these records, it seems that rural schools do not ensure sufficient information sharing. The mean responses in assessing the level of information sharing, according to teachers, in rural areas, as per table 8, were 2.5968 (DS. 52272). The purpose of the study was to understand the interconnection middle the level of involvement and the level of information between teachers from rural areas and family, according to family attitudes. In terms of correlation between the meetings and information shared in rural areas, the rate is: $(r=$. $\left.652^{* *}, \mathrm{p}<0.00\right)$, again a weak link, but yet again statistically relevant.

Here we have some discordance in perception. According to the findings, families of both areas state that they are not provided with information on prevention of violence amongst students at school, while teachers have a different perception on such a matter, according to them, the families are given sufficient information on matters related to students and families. All schools surveyed give the result that 176 teachers have read the Kosovo Law on Education. This means that teachers are not aware of the legal aspects. Families also show a poor level of awareness on legal information, but this is less concerning, when compared to teachers which are bound to know such terms. Meanwhile, all directors surveyed seem to be aware of legal terms. Also, we have identified the fact that schools do not offer families proper information on forms and options of cooperation. The main concern in relation with prevention of violence amongst youth is the fact that the school does not provide regular and continuous information to families on the potential changes in behaviour of children.

Interviews have revealed a rather worrying issue and the fact that a part of the psychological violence among students is not reported in family or school. It seems that the reason for not denouncing it is family's lack of information about psychological violence and its consequences. But, this non-denunciation, could it be that it enables violence among them "stand tall"? During interviews with family, they thought they were familiar with the concept of violence but it resulted that they were not able to define it as a notion. They also lacked information about consequences of violence. A part of them are informed but this information is not specific. When we are at information, through interviewing family and school, we understand that the reason of violence among students is the fact that students are not informed about the 
consequences for them in case of violence. Further, one of the school directors considers that "even education law itself does not clearly define duties and responsibilities of students in school. If we analyse the law of primary and secondary education in Kosovo, we do not find it meaningful enough in this direction" (Personal communication, Director).

Worrying is the fact that while the interviewees declare that violence is harmful and it must be stopped, they are not informed and show surprise when it is talked about preventing it. Oddly, we encounter the same situation among teachers as well. We notice a "hopelessness" toward preventing violence among students in school. A teacher even states that "in our time we have also teased each other", another teacher says that "it is difficult to deal with this generation", while two parents think that "violence between students is a little bit exaggerated". Violence among students in school is prohibited by law, but this study finds that family lacks adequate information about the consequences of violence. School does not fulfill its duty at this point. In one of the schools in capital city, teachers are satisfied with the fact that there is some information displayed on noticeboards in the school hall, which indeed, is not nearly enough. The findings suggest paying more attention to this issue. Interviewing with parents reveals that school should contact family more often. "They can inform us about any change in child's behaviour. Today, we have internet, phones, but they do not contact us about violence, only when the problem becomes very serious" (Parent).

Interviews with school directors reveal that there has been no organization of trainings for teachers and directors about the importance of involving family in school, or about preventing violence among students at school. From interviews with family, it is found that they want to be more involved in preventing violence among students in school. One of often stated pronunciations about this issue is: "We are busy with work, but if they are afternoon meetings, why not? From nine interviewed families, $70 \%$ of them state that they lack information about preventing violence among students, while there are no families which declare that they are involved in any school activity about preventing violence in school. From teachers and school directors' side, interviews enable us understand that school has no strategy and has not organized any activity about preventing violence among students. We encountered such position in $88 \%$ of the interviewed families. Among teachers we have the statement that "we try to contact family", but they do not explicitly talk about any real activity in this direction.

\section{DISCUSSION AND CONCLUSION}

Teachers have an important role in the occurrence and prevention of violent acts at schools (Yavuzer, Gundogdu \& Dikici, 2009). In addition, the school explains to them about policies, the school's programs, the school's rules, and the school's regulations (Wulandary,D \& Herlisa, 2017). This study has a very useful purpose on the finding of the relationship between the exchange of information between teachers and parents and the level of involvement of parents in school in with the objective of preventing violence between students. The results obtained from the correlation analysis show the correlation between variables. All correlations are with the significant value of $p=.000$. The findings show a positive and significant relation between these two variables, but of 
the moderated level. Based on this fact, the recommendation for the next study also turns out in the direction of the ascertainment of the way the information is exchanged between these two factors, their quality and the professional development of teachers on this aspect.

The findings of this study showed that a significant relationship exists between between information and parents' involvement in school-based violence prevention. This finding also corroborates the study of Otani (2019) informing parents about school was positively associated with home-based parental involvement. Whereas, based on qualitative data shown in the study, information shared by school, in general terms, including matters related to students, or even those related to violence, is not perceived as sufficient, or it is even found to be poor. Families are not informed on ways of preventing violence through their own children. On the other hand, teachers consider that it is well-placed in this regard. Similarly and the researcher. Loudová (2013) in his study suggest the school for communicative communication with parents in order to strengthen mutual trust and mutual understanding.

In this factor there is a visible discordance of perceptions. The analysis of quantitative findings shows that: $62 \%$ of urban families have the perception that the information from their schools is poor. $30 \%$ of the families perceives the level of information to be of medium level, while from a total of 300 surveyed, only $3.2 \%$ perceive the level of information sharing from the schools to be high. Also, according to teachers in urban areas, information to the families is of a medium level, according to $64 \%$ of the teachers in these areas, while $22 \%$ perceive it to be "high" level of information shared with the families. According to table 66 data, from 393 families surveyed in rural areas, $36 \%$ of these families perceive the level of information shared from the schools to be "poor", while $34 \%$ consider it to be "medium". The positions of rural families on the level of information shared by the schools do not have distinct differences in levels. The information shared by the schools in rural areas, according the families in these areas, vary between medium and poor levels. Teachers of the same areas assess the information sharing to be of medium quality. From 315 surveyed, 117 (17.9\%) perceive the level of information shared with the families to be "medium", 193 state that the level of information is "high", and only 5 of the teachers say it is "poor". According to rural teachers, information shared by their schools with families is of "high" quality meaning they provide sufficient information to families. This interconnection between information, communication and the level of meetings is an important occasion because, as information and communication involves encoding messages and it serves various goals in multiple levels of occupational, personal and social domains (Stamatis. 2013).

The study shows that there is no coordination, or such cooperation is not properly established in terms of preventing violence amongst students, while there is insufficient sharing of information in this regard. The spheres of influencing students remain divided. They may also include negative experiences with the school. Other obstacles that may possibly face in front of family members during their child's education are the limited inclinations for their role in the educational process, low sense of efficiency to help the success of the child in school, as well as the negative perception for invitations 
and opportunities for inclusion. And external school variables and within-school variables can mediate contributions from external contexts, findings show that school violence is highly influenced by the transaction of the students' experiences in various social environments or contexts. Researches Deslandes,R \& Bertrand, R. (2010) find that parents' perceptions of teacher invitations were associated with parent involvement at school across the 3 grade levels. Whether at home or at school, parents became involved if they perceived that teachers and students expected or desired their involvement.

Families who have not been invited by the school may not understand the importance of their involvement (Callender \& Hansen, 2004). The theoretical model of Benbenishty and Astor (2005), which states that school violence is associated with a combination of numerous within- and external school variables and within-school variables can mediate contributions from external contexts, findings show that school violence is highly influenced by the transaction of the students' experiences in various social environments or contexts.

According to Brubaker et al, (2001) each parent has had interactions with the school. Families or its members, if they have had good experiences with the school, are likely to be easily included in the school when invited. While the authors (Brewster \& Railsback, 2003) consider that family members whose experiences have been negative may not be comfortable when entering the school building or may not believe that teachers appreciate the contribution of them. Families who have had problems with a teacher or other school, their children may questioned the value of communicating with the school. Families are not influenced by school information on violence in preventing such violence in their children. Our schools places its attention on communication of student achievements at school, or only communicating the scores of students, but not on informing families on most efficient ways of cooperating with them in awareness raising on violence amongst students. The levels of information sharing from the school in terms of violence amongst youth is shown to be rather concerning for families. On the other hand, if families whose children are violent or violated, would be more involved (present) with schools, they would be well informed on any changes in the behaviour of their children. Further, when families are well informed of the behaviour of their children at school, be it related to harassment, slander or any other problems children have, there is bound to be more cooperation with schools, and prevention of violence between children becomes possible. Based on a study conducted in Kosovo by the authors Pupovci and Tafarshiku (2002), it is noticeable that there exists a very good will of parents to get involved in different activities in school, but $39.7 \%$ of the executives surveyed declare that parents do help the process of teaching and finding the ways of contributing for the learning process

Partnership must be managed well, otherwise, it can lead to a genuine conflict between opposing systems of rules to the requirements of the child by family, school or group of friends to be antagonistic (Blandul, 2005). In their study (1989), Epstein and Douber have found that teachers who have more positive views on parent involvement pay more attention to others from practices such as organizing meetings with parents of all 
students for school curricula and exchanging with parents both negative and positive outcomes of their students. When teachers make parental involvement part of daily teaching practices, parents increase interaction with their children at home, have the most positive feelings about their ability to help their children, have higher appreciation for teachers in general and students improve their attitude and achievements (Epstein, 2001). Also, according to scientific research, co-operation programs and schoolcommunity partnerships and teacher-related parental involvement schemes have a very positive effect on parents' ability to help their children throughout school years; in assessing the parents about the skills of teachers and the quality of teaching; in the opinion of the teachers on the parents 'opportunities to help their children with the school's home assignments and students' thinking about school (Becker \& Epstein, 1982; Epstein 2001).

Descriptive data renders us aware that school is rather formalistic in informing families, while qualitative data reflect a lack of information. Deriving from an analysis of interviews, schools provide little or no information to families in terms of preventing violence between children at school. On the other hand, correlational data render clear that information sharing is an essential factor of statistical relevance of the quality of school-family relationships. The correlational results take us to the requirement of improving the level of information shared from school, which we consider to be of primary importance. The lack of information, to be shared from school to family and from family to school, on violence amongst students and prevention thereof, can only result in lack of results in prevention, or failure of prevention of violence. No prevention can be imagined without cross-referenced information.

In conclusion, there are two contradictory findings among parents and school regarding their perceptions and practices informing about violence among students in school. Interviews have revealed a rather worrying issue and the fact that a part of the psychological violence among students is not reported in family or school. Violence among students in school is prohibited by law, but this study finds that family lacks adequate information about the consequences of violence. From teachers and school directors' side, interviews enable us understand that school has no strategy and has not organized any activity about preventing violence among students. The main concern in relation with prevention of violence amongst youth is the fact that the school does not provide regular and continuous information to families on the potential changes in behaviour of children.

\section{Further Research}

This study may be limited by the following factors: Teachers may be cautious in providing information in collaboration with the family; Restrictions on giving honest responses may also encounter family.

The current study is one of the first studies conducted in the country with the aim of analyse the level of informing of family from the school and the impact of this factor on the level of school-to-family meetings. Supported on all the stages and characteristics of 
the study, especially in the results, it is suggested the possibility for other studies in this area. Recommendations for further studies consist of:

Studies with longitudinal design, will could to offers very valuable data on the influence of informationing as a factor in changing aggressive and violent behavior of pupils; Through deliberate sampling, to be realized a qualitative study with the parents of the violent pupils, and to be explored their attitudes on factors, such as the communication and informationing of the school to them, where we will identify the prohibitive elements of these factors in partnership; Long-term studies to understand that what could be the best practice for school in order to ensure a bigger involvement of family in school with the aim of preventing violence among pupils.

\section{REFERENCES}

Altun, S., \& Baker, Ö. (2010). School violence: a qualitative case study. Procedia Social and Beh. Sci. ,2(2). 3165-3169. http://dx.doi.org/10.1016/j.sbspro.2010.03.483.

Amanda, L. W., \& Susan, M. Sh . (2011). Family Engagement in Rural Schools.

Arias, M. B., \& Morillo-Campbell, M. (2008). Promoting ELL parental involvement: Challenges in contested times. Education Policy Research Unit. Arizona State University. Retrieved from http://epsl.asu.edu/epru/documents/EPSL-0801-250EPRU.pdf.

Becker, H. J., \& Epstein, J. L. (1982). Parent involvement: A survey of teacher practices. The Elementary School J., 83(2), 85-102. http://dx.doi.org/10.1086/461297.

Bezati, F., \& Hoxhalari, R. (2011). Përfshirja e prindërve ne jetën e shkollës [Parental involvement in school life]: Tirane

Blandul, V. (2005). Introduction in problems of special psycho-pedagogy. Oradea: University of Oradea Press.

Brewster, C., \& Railsback, J. (2003). Building trust with schools and diverse families. implications for principals and teacher northwest regional. Retrieved from http:/www/digitalcommons.unl.edu.

Brubaker, T. H., Brubaker, E., \& Link, M. (2001). School violence: Partnerships with families for school reform. Michigan Family Review, 6(1),1-11.

Callender, S., \& Hansen, A. (2004). Family-school partnerships: Information and approaches for educators. Helping Schildren at Home and School II: Handouts for Families and Educators. NASP.

Creswell, J, W. (2003). Research design: Qualitative, quantitative and mixed methods approaches. Thousand Oaks, CA: Sage

Dusi, P. (2012). The family-school relationships in Europe: A research review. C E S P Journal, 2(1), 13-21. 
Epstein, J. L. (1986). Parents' reactions to teacher practices of parent involvement. Elementary School Journal, 86, 277-294.

Epstein, J. L. (2001). School, family and community partnerships: Preparing educators and improving schools. Boulder, CO: Center on School, Family and Community Partnerships, Johns Hopkins University: Westview Press.

Epstein, J. L., \& Dauber, S. L. (1989). Teacher attitudes and practices of parent involvement in inner-city elementary and middle schools. CREMS Report No 32. Baltimore: John Hopkins U., Center for Research in Elementary and Middle Schools.

Epstein, N. B. Bishop, D., Ryan, C., M., \& Keitner, G. (1993). The momaster model view of healthy family functioning. In F. Walsh (Eds.), Normal family processes (pp. 138-160). New York/London: The Guilford Press

Erlendsdottir, G. (2010). Effects of parental involvement in education (Unpublished master thesis). University of Iceland School of Education. National Coalition for Parent Involvement in Education.

Georgiou, S. N. (2007). Parental involvement: beyond demographics. International Journal about Parents in Education, 1, 59-62.

Grahame, D. (2002). Creating corporate reputations: Identity, image, and performance: Oxford University Press.

Jackson Ch, Henrikson, L., \& Foshee, V. (1998). The authoritative parenting index: Predicting health risk behaviors among children and adolescents. Health education \& Behavior, 25(3), 319-37. https://doi.org/10.1177/109019819802500307.

Lašek, J., \& Loudová, I. (2013). Rodina jako základ vývoje morálky a občanských postojů dětí. Hradec Králové: Gaudeamus.

Lerner R M. (2006). Developmental science, developmental systems, and contemporary theories of human development. In W. Damon, R. M. Lerner (Eds.), Handbook of child psychology, Vol. 1: Theoretical models of human development. 6 (pp.1-17). Hoboken, NJ: Wiley.

Raffael, K., \& Linda, M. (1999). Improving home-school collaboration with disadvantaged families: Organizational principles, perspectives, and approaches. School Psychology Review, 28(3), 448-469

Ratcliff, N., \& Hunt, G. (2009). Building teacher-family partnerships: The role of teacher preparation programs. Education, 129(3), 495-505.

Schalla, L. (2015). Family-school collaboration in Mexico: Perspectives of teachers and parents (Unpublished doctoral thesis). University of Minnesota.

Shapley, \& Case. (2004). Building partnership with parents. Received from htp://images.pearsonclinical.com/images/PDF/assessmentReports/Building_Partnerships _with_Parents.pdf. 
Stamatis, P. J. (2013). Communication in education. Athens: Diadrassi Publications.

American Psychological Association. (1993). Violence and youth: Psychology's response: Vol 1: Summary Report of the American Psychological Association Commission on Violence and Youth. Washington, DC: Author.

Benbenishty, R. A. (2005). School violence in context: Culture, neighborhood, family, school, and gender. New York: Oxford University Press

Buchanan, A. (1996). Cycles of child maltreatment: Facts, fallacies and interventions. Crime and safety. Washington, DC: US Department of Education and Justice.

Devoe, J. F., Peter, K., Noonan, M., Snyder, T., \& Baum, K. (2005). Indicators of school crime and safety: 2005. US: Department of Education, Institute of Education Sciences.

Gottfredson, M., \& Hirschi, T. (1990). A general theory of crime. Stanford, CA: Stanford U.

Kang, J. C., \& Aston, R. A. (2011). Students' personal traits, violence exposure, family factors, school dynamics and the perpetration of violence in Taiwanese elementary schools. Health Education Research, 26(1), 150-166.

Kolbert, B, J., Schultz, D., \& Crothers, M, L. (2014). Bullying prevention and the parent involvement model. Journal of School Counseling, 12(7).

Lang, S. (1998). Researcher: Economic indicators hide hardships faced by U.S. children. Retrieved from http://www.news.cornell.edu.

Loeber, R., \& Stouthamer-Loeber, M. (1986). Family factors as correlates and predictors of juvenile conduct problems and delinquency. In M. H. Tonry, \& N. Morris (Eds.), Crime and justice: An annual review of research, Vol. 7 (pp. 29-149). Chicago: University of Chicago Press.

Mason, E. M., \& Schultz, D. R. (2013). Tweet your way to professional development. ASCA School Counselor, 50, 24-29.

Miller, M. A. (1996). Coping with weapons and violence in school and on your streets. New York: Rosen Publishing Group.

Sampson, D. (2013). Get on the blogging bandwagon. ASCA School Counselor, 50, 1217.

Shore, K. (2005). The abcs of bullying prevention: Understanding school bullying. University Press.

Walker, D. (1995). School violence prevention. Wiley: Chichester.

Yavuzer, Y., Gundogdu, R., \& Dikici, A. (2009). Teachers' perceptions about school violence in one turkish city. Journal of School Violence, 8(1), 29-41. http://dx.doi.org/10.1080/15388220802067797. 